Article

\title{
Fertility and Iron Bioaccumulation in Drosophila melanogaster Fed with Magnetite Nanoparticles Using a Validated Method
}

\author{
Fernanda Pilaquinga ${ }^{1,2}, * \mathbb{D}$, Sofía Cárdenas ${ }^{1}$, Doris Vela ${ }^{3}$, Eliza Jara ${ }^{1}$, Jeroni Morey ${ }^{2}$, \\ José Luis Gutiérrez-Coronado ${ }^{4}$, Alexis Debut ${ }^{5}\left[\right.$ and María de las Nieves Piña ${ }^{2}{ }^{\mathbb{C}}$ \\ 1 Laboratorio de Nanotecnología, Escuela de Ciencias Químicas, Pontificia Universidad Católica del Ecuador, \\ Avenida 12 de Octubre 1076 y Roca, Quito 17-01-2184, Ecuador; aneleaifos@hotmail.com (S.C.); \\ enjara@puce.edu.ec (E.J.) \\ 2 Department of Chemistry, University of the Balearic Islands, Cra. de Valldemossa Km. 7.5, \\ 07122 Palma de Mallorca, Spain; Jeroni.morey@uib.es (J.M.); Neus.pinya@uib.es (M.d.1.N.P.) \\ 3 Laboratorio de Genética Evolutiva, Escuela de Ciencias Biológicas, Pontificia Universidad Católica del \\ Ecuador, Avenida 12 de Octubre 1076 y Roca, Quito 17-01-2184, Ecuador; dvela508@puce.edu.ec \\ 4 Department of Applied Physica Chemistry, Universidad Autónoma de Madrid, 28049 Madrid, Spain; \\ josluguc@gmail.com \\ 5 CENCINAT, Universidad de las Fuerzas Armadas ESPE, Sangolquí 170501, Ecuador; apdebut@espe.edu.ec \\ * Correspondence: mfpilaquingaf@puce.edu.ec; Tel.: +593-996725197
}

\section{check for}

updates

Citation: Pilaquinga, F.; Cárdenas, S.; Vela, D.; Jara, E.; Morey, J.; GutiérrezCoronado, J.L.; Debut, A.; Piña, M.d.1.N. Fertility and Iron Bioaccumulation in Drosophila melanogaster Fed with Magnetite Nanoparticles Using a Validated Method. Molecules 2021, 26, 2808 https://doi.org/10.3390/ molecules 26092808

Academic Editor: Iwona Cicha

Received: 31 January 2021

Accepted: 16 April 2021

Published: 10 May 2021

Publisher's Note: MDPI stays neutral with regard to jurisdictional claims in published maps and institutional affiliations.

Copyright: (c) 2021 by the authors. Licensee MDPI, Basel, Switzerland. This article is an open access article distributed under the terms and conditions of the Creative Commons Attribution (CC BY) license (https:/ / creativecommons.org/licenses/by/ $4.0 /)$.

\begin{abstract}
Research on nanomaterial exposure-related health risks is still quite limited; this includes standardizing methods for measuring metals in living organisms. Thus, this study validated an atomic absorption spectrophotometry method to determine fertility and bioaccumulated iron content in Drosophila melanogaster flies after feeding them magnetite nanoparticles $\left(\mathrm{Fe}_{3} \mathrm{O}_{4} \mathrm{NPs}\right)$ dosed in a culture medium $\left(100,250,500\right.$, and $\left.1000 \mathrm{mg} \mathrm{kg}^{-1}\right)$. Some NPs were also coated with chitosan to compare iron assimilation. Considering both accuracy and precision, results showed the method was optimal for concentrations greater than $20 \mathrm{mg} \mathrm{L}^{-1}$. Recovery values were considered optimum within the $95-105 \%$ range. Regarding fertility, offspring for each coated and non-coated NPs concentration decreased in relation to the control group. Flies exposed to $100 \mathrm{mg} \mathrm{L}^{-1}$ of coated NPs presented the lowest fertility level and highest bioaccumulation factor. Despite an association between iron bioaccumulation and NPs concentration, the $500 \mathrm{mg} \mathrm{L}^{-1}$ dose of coated and non-coated NPs showed similar iron concentrations to those of the control group. Thus, Drosophila flies' fertility decreased after NPs exposure, while iron bioaccumulation was related to NPs concentration and coating. We determined this method can overcome sample limitations and biological matrix-associated heterogeneity, thus allowing for bioaccumulated iron detection regardless of exposure to coated or non-coated magnetite NPs, meaning this protocol could be applicable with any type of iron NPs.
\end{abstract}

Keywords: magnetite nanoparticles; chitosan; Drosophila melanogaster; iron bioaccumulation; fertility

\section{Introduction}

Nanotechnology has made it possible for biomedical applications and diagnostics to create, characterize, and modify the functional properties of nanoparticles (NPs) [1]. Inorganic NPs mediate between the molecular and solid states and combine physical and bulk phase properties with chemical accessibility in solution [2]. Thus, they are ideal elements for building nanostructured materials and devices with physical and chemical properties that are customizable. In addition, NPs have physical and chemical properties that differ from both the atom and the equivalent of the bulk counterparts. Magnetic NPs have a large surface area and exhibit quantum size effects, both of which drastically change some of the magnetic properties and exhibit superparamagnetic phenomena and magnetization quantum tunneling, as each particle can be treated as a single magnetic domain [3]. 
Iron NPs are especially useful in nanotechnology. This metal is an essential element that performs very important functions in living beings [4]; therefore, iron poisoning is rare [5]. Iron poisoning severity is related to the amount of ingested elemental iron [6]; since the human body does not have efficient mechanisms for excreting large amounts of iron, intoxication from a high intake $\left(>60 \mathrm{mg} \mathrm{kg}^{-1}\right)$ of this metal can be lethal [7]. Iron oxides are used as nanosized magnetic particles (i.e., maghemite $\left[\gamma-\mathrm{Fe}_{2} \mathrm{O}_{3}\right]$ or magnetite $\left[\mathrm{Fe}_{3} \mathrm{O}_{4}\right]$ with single-domain diameters of approximately 5-20 nm); magnetite $\left(\mathrm{Fe}_{3} \mathrm{O}_{4} \mathrm{NPs}\right)$ is a better choice in terms of biocompatibility [8]. $\mathrm{Fe}_{3} \mathrm{O}_{4}$ is a typical magnetic iron oxide with an inverse spinel structure [9], and at room temperature, its electrons can hop in the octahedral sites between $2+$ and $3+$ ion oxidation states, making magnetite an important element of the semi-metallic material class [10]. These magnetic NPs can be dispersed into suitable solvents with the proper surface coating, forming homogeneous suspensions called ferrofluids [11]. Ferrofluids constitute colloids in which magnetic NPs are distributed and stabilized in a liquid carrier. Such a suspension can connect with an external magnetic field and be positioned to a particular region, allowing for magnetic resonance imaging for medical diagnosis and AC magnetic field-assisted cancer therapy [12]. Current potential applications of magnetic NPs are continuously advancing and include guided drug and gene delivery [13], tissue engineering [14], magnetic resonance imaging [15], enzyme immobilization [16], and protein and metal adsorption [17].

NPs are sometimes coated with various materials to enhance their advantages, for example with chitosan (Ch). Among the most abundant polysaccharides, after cellulose and hemicellulose, is chitosan, which is biodegradable and non-toxic and is produced through deacetylation of chitin [18]. Free amino and hydroxyl groups are present in the chitosan that enable NPs to bind to different chemical groups and ions, facilitating different applications, such as protein and metal adsorption, directed delivery of drugs and genes, magnetic resonance imaging, tissue engineering, and immobilization of enzymes. In addition, this form of NPs could be used for the destruction of malignant cells in hyperthermia treatment [19]. However, few papers have focused on chitosan [20] and its nanotoxicology with magnetite NPs in in vivo tests [21,22].

Given the limitations of in vivo experimentation, the use of insects as a model organism is considered a valid starting point to extrapolate the findings to other living beings. Among insects, Drosophila melanogaster has a biological system suitable for the study and detection of chemical species, which has been determined after extensive study of its genetics [23]. Drosophila as a test system has several advantages: it is a eukaryotic organism with sexual dimorphism [24] (i.e., the male can be easily distinguished from the female), a large number of individuals can be obtained in a small space at low cost [25], and its life cycle lasts 10 to 12 days [26] at $25^{\circ} \mathrm{C}$ and $60 \%$ relative humidity [27]. Thus, Drosophila melanogaster can be used to rapidly test for nanotoxicity and then ascertain its underlying mechanisms.

Some toxicity studies related to Drosophila melanogaster survival after $\mathrm{Fe}_{3} \mathrm{O}_{4} \mathrm{NPs}$ exposure have been carried out [28], but they cover iron bioaccumulation in fly eggs, not adult flies [29]. There are also reports regarding the effects of magnetite on fly longevity [30] and fertility $[28,30,31]$. Vecchio et al. [32] indicated the high toxicity of $\mathrm{Fe}_{3} \mathrm{O}_{4} \mathrm{NPs}$ for fertility in Drosophila melanogaster, but only at low concentrations (1.91-38.5 $\left.\mathrm{g} \mathrm{g} \mathrm{g}^{-1}\right)$. According to the toxicity ranking of metal NPs for Drosophila, non-coated $\mathrm{Fe}_{3} \mathrm{O}_{4} \mathrm{NPs}$ take third place, after silver and cobalt NPs, respectively [32], but bioaccumulated concentrations of each metal have not been studied. In other investigations $[33,34]$ with eggs and male adult flies exposed to food containing AgNPs, NPs exposure was found to shorten their lifespan but not to lower their exposure to $\mathrm{Ag}$ ions $\left(\mathrm{AgNO}_{3}\right)$. On the other hand, $\mathrm{AgNPs}$ of $20-30 \mathrm{~nm}$ displayed less toxicity than larger of 500-1200 nm, implying that there is a nanotoxicity scale for silver particles $[35,36]$. The lifespan of Drosophila melanogaster can therefore be used to examine NPs toxicity metrics, given the finding that its lifespan can be shortened by the total amount of ingested NPs but not by their total surface area. 
Reactive oxygen species (ROS) have been identified as the primary cause of toxicity induced by nanomaterials such as TiNPs [37] and AuNPs [38,39]. The intracellular ROS level in Drosophila was found to have increased in this study after oral ingestion of different sizes of NPs. However, various NPs sizes had no impact on the development of ROS, suggesting that the total surface area of NPs is not a significant parameter for oxidative stress induction. Melanization and cuticle development defects were a consequence for adult Drosophila melanogaster fed with NPs, which indicates that Drosophila can also be used to research metabolic disorders caused by nanomaterials; nonetheless, further studies are needed to better understand pigmentation defects [38].

This study aimed to validate an analytical method for measuring iron bioaccumulation in Drosophila melanogaster flies fed with magnetite NPs regarding limits of detection and quantitation. Chitosan was used as a coating to compare iron concentration determination and verify its effect on fly fertility. Four different $\mathrm{Fe}_{3} \mathrm{O}_{4} \mathrm{NPs}$ concentrations (100, 250, 500 , and $1000 \mathrm{mg} \mathrm{L}^{-1}$ ) were tested to determine changes in the number of offspring after exposure, as well as iron bioaccumulation.

\section{Results}

\section{1. $\mathrm{Fe}_{3} \mathrm{O}_{4} \mathrm{NPs}$ and $\mathrm{Ch}-\mathrm{Fe}_{3} \mathrm{O}_{4} \mathrm{NPs}$ Synthesis and Characterization}

In Figure 1, the TEM image and size distribution of synthesized $\mathrm{Fe}_{3} \mathrm{O}_{4} \mathrm{NPs}$ and Ch$\mathrm{Fe}_{3} \mathrm{O}_{4} \mathrm{NPs}$ can be observed. As can be seen in the TEM Figure 1a,b, due to the ferromagnetic nature of the magnetite structure, the NPs were not perfectly dispersed but tended to form some aggregates, which, in this case, had at maximum a diameter of approximately $600 \mathrm{~nm}$. Obtained NPs were quasi-spherical, and their estimated average size were $13.96 \pm 4.49$ (Figure 1c) and $18.7 \pm 5.20 \mathrm{~nm}$ (Figure 1d), respectively, as measured using the Fiji software. Magnetite crystalline nature was confirmed from the XRD analysis. A magnetite structure of $\mathrm{Fe}_{3} \mathrm{O}_{4} \mathrm{NPs}$ is also shown in the diffractogram in Figure 2; the bottom of the diffractogram curves correspond to the amorphous part of the glass that served as support, and of the amorphous phase of the extract. There are two diffraction peaks at $35.3^{\circ}$ and $44.6^{\circ}$ corresponding to magnetite formation on the (111) and (131) planes in $\mathrm{Fe}_{3} \mathrm{O}_{4} \mathrm{NPs}$ (Figure 2a) and in Figure 2b.

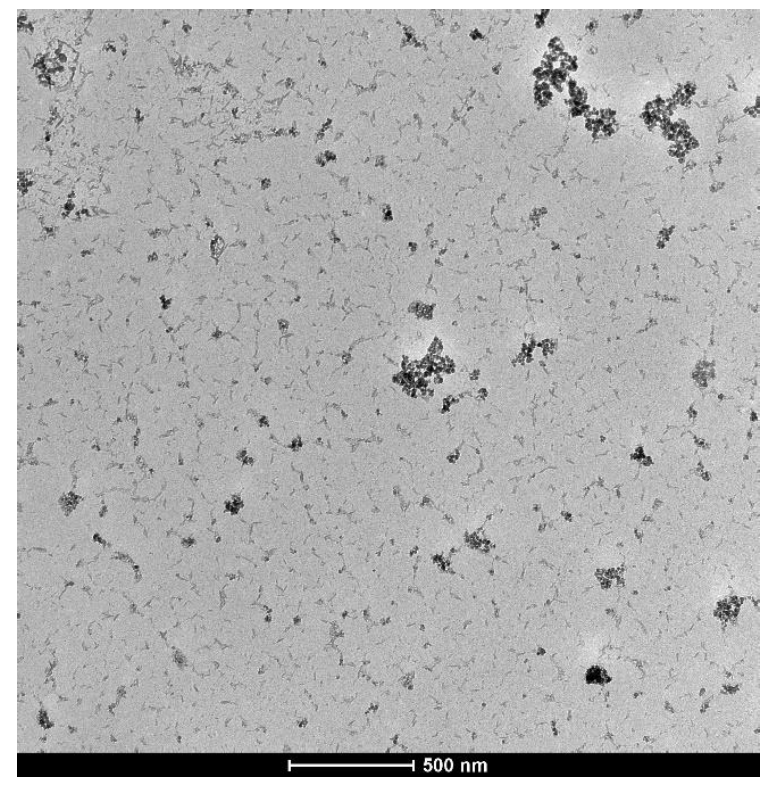

(a)

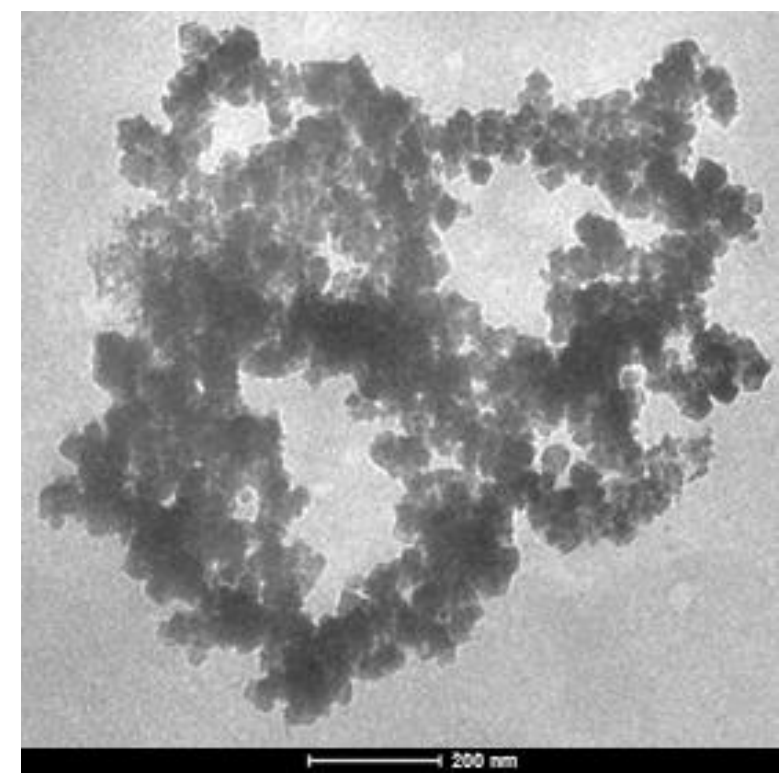

(b)

Figure 1. Cont. 


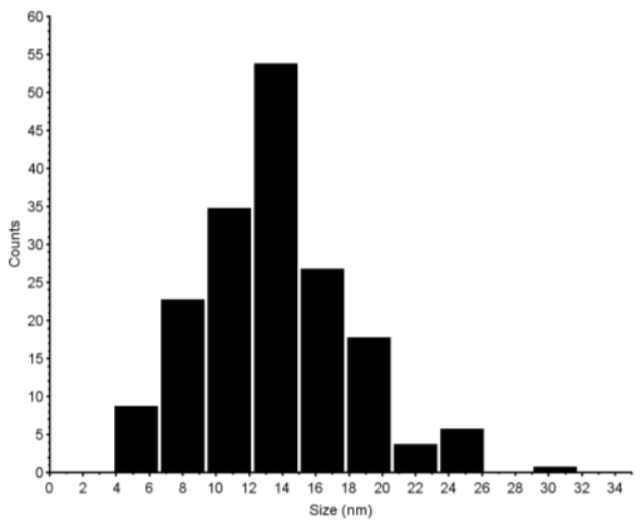

(c)

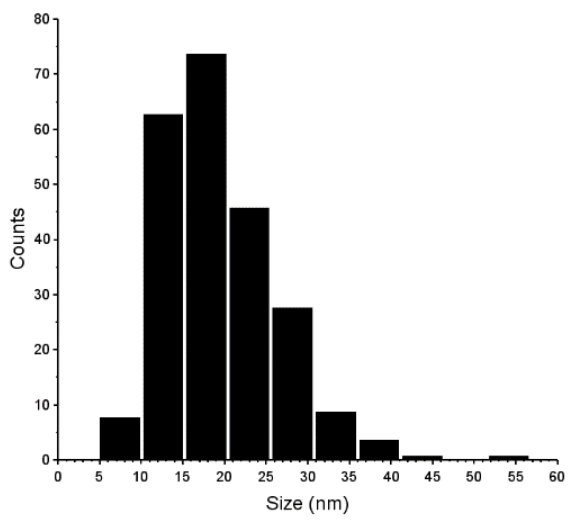

(d)

Figure 1. Magnetite NPs characterization: TEM image of $\mathrm{Fe}_{3} \mathrm{O}_{4} \mathrm{NPs}(\mathbf{a}) \mathrm{Ch}-\mathrm{Fe}_{3} \mathrm{O}_{4} \mathrm{NPs}$ (b) and size distribution histogram $\mathrm{Fe}_{3} \mathrm{O}_{4} \mathrm{NPs}(\mathbf{c}) \mathrm{Ch}-\mathrm{Fe}_{3} \mathrm{O}_{4} \mathrm{NPs}(\mathbf{d})$.

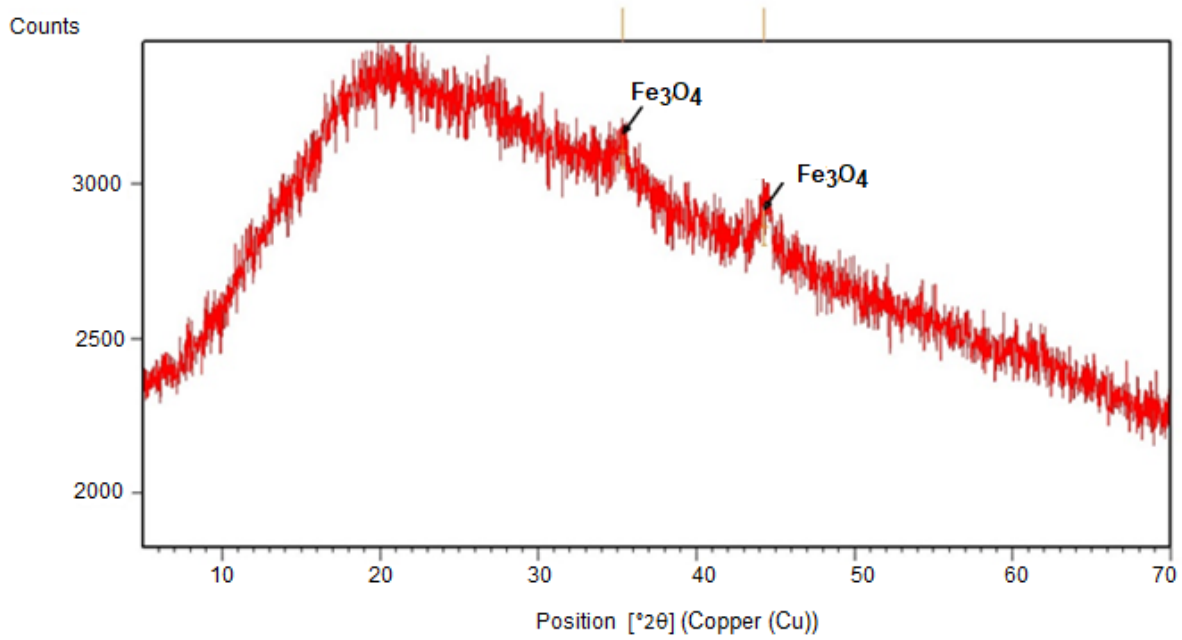

(a)

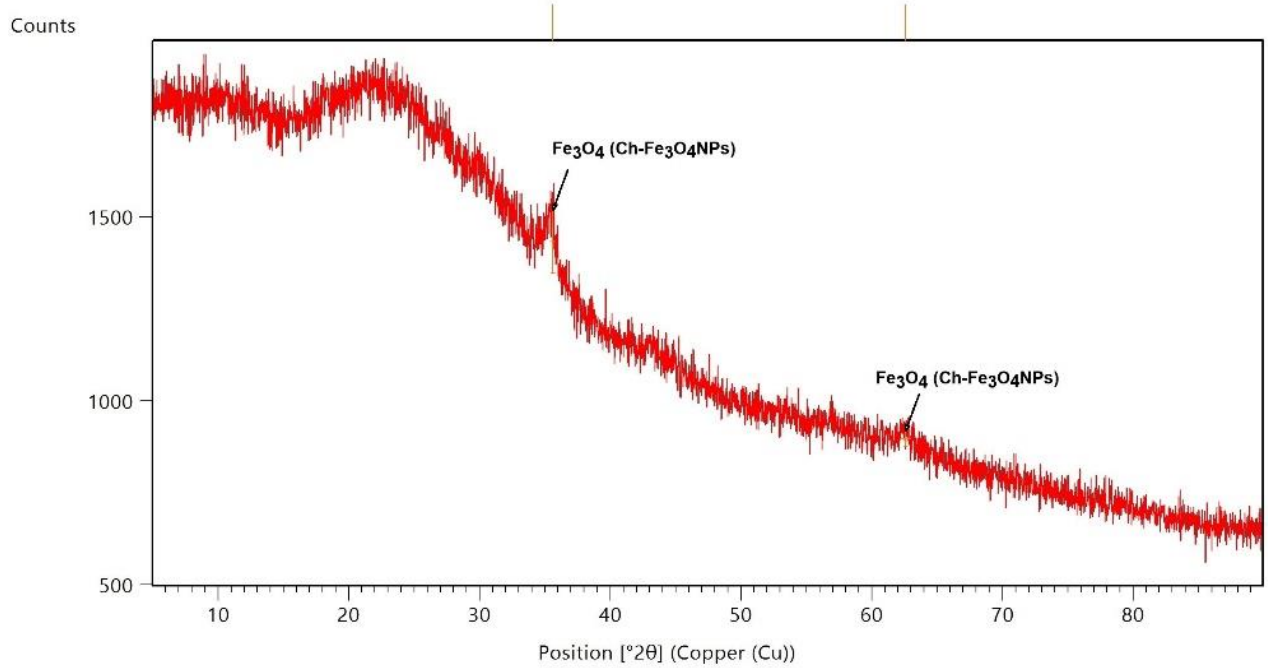

(b)

Figure 2. X-ray diffractograms: $\mathrm{Fe}_{3} \mathrm{O}_{4} \mathrm{NPs}(\mathbf{a})$ and $\mathrm{Ch}-\mathrm{Fe}_{3} \mathrm{O}_{4} \mathrm{NPs}(\mathbf{b})$. 
It is found that Bragg Reflection peaks at $36.06^{\circ}$ coincide with the cubic phase of $\mathrm{Fe}_{3} \mathrm{O}_{4}$ (ICSD: 96012). The lattice parameter and highest intensity plane (113) are well matched and agree with other reported patterns. Hematite or metal hydroxides were not identified, which confirms the complete formation of $\mathrm{Fe}_{3} \mathrm{O}_{4}$.

In Figure 3, the zeta potential distribution for $\mathrm{Fe}_{3} \mathrm{O}_{4} \mathrm{NPs}$ (red) and $\mathrm{Ch}-\mathrm{Fe}_{3} \mathrm{O}_{4} \mathrm{NPs}$ (green) are shown. The value of $-36.3 \mathrm{mV}$ for $\mathrm{Fe}_{3} \mathrm{O}_{4} \mathrm{NPs}$ is compatible with the nonfunctionalization with a high-density negative charge [40]. The presence of chitosan on the surface of $\mathrm{Ch}-\mathrm{Fe}_{3} \mathrm{O}_{4} \mathrm{NPs}$ modifies this value until $-19.3 \mathrm{mV}$. The values of polydispersity index (PDI) were 0.28 and 0.34 respectively, demonstrating that the particle size distribution is uniform in both cases, as well as good suspension stability [41].

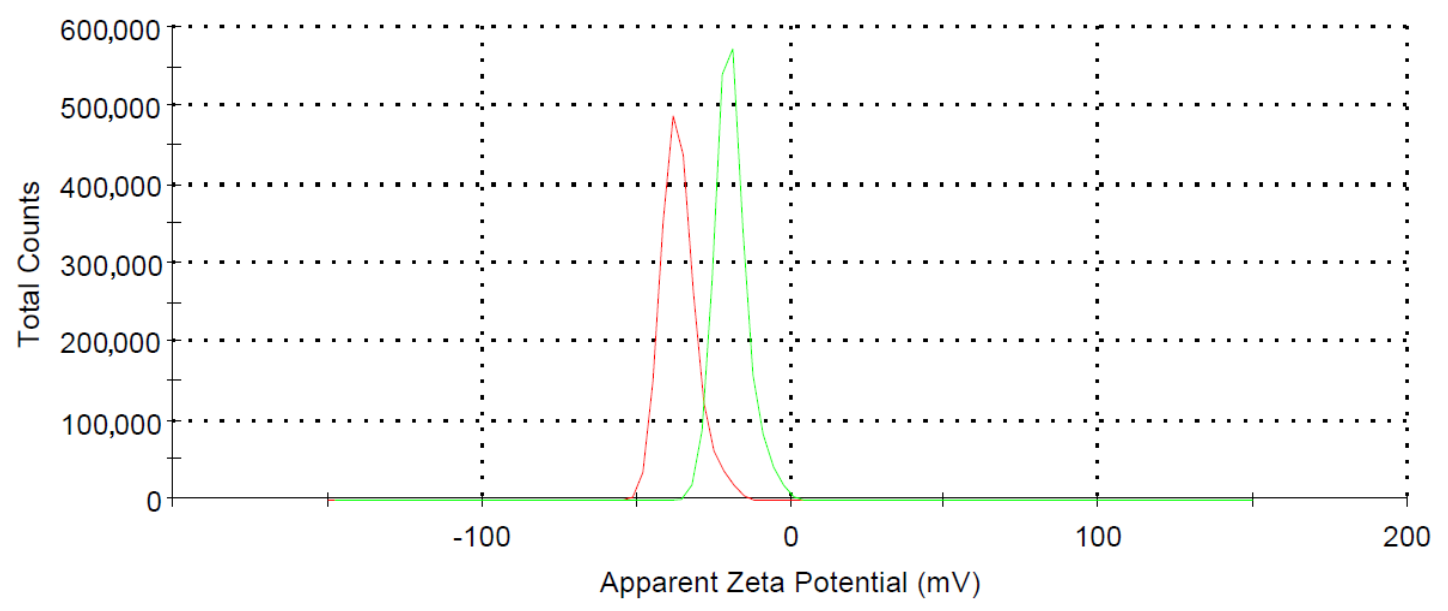

Figure 3. Zeta potential distribution: $\mathrm{Fe}_{3} \mathrm{O}_{4} \mathrm{NPs}$ (red) and $\mathrm{Ch}-\mathrm{Fe}_{3} \mathrm{O}_{4} \mathrm{NPs}$ (green).

\section{2. $\mathrm{Fe}_{3} \mathrm{O}_{4} \mathrm{NPs}^{\prime}$ and $\mathrm{Ch}-\mathrm{Fe}_{3} \mathrm{O}_{4} \mathrm{NPs}^{\prime}$ Effects on Drosophila melanogaster Fertility}

The offspring of crossed flies exposed to $\mathrm{Fe}_{3} \mathrm{O}_{4} \mathrm{NPs}$ and chitosan-coated (Ch- $\mathrm{Fe}_{3} \mathrm{O}_{4} \mathrm{NPs}$ ) were counted to estimate the effect of four NPs concentrations on the fertility of flies after exposure (Figure 4). The offspring of the control crosses (flies not exposed to NPs) were also counted.

\section{Non-coated $\quad$ Ch-coated}

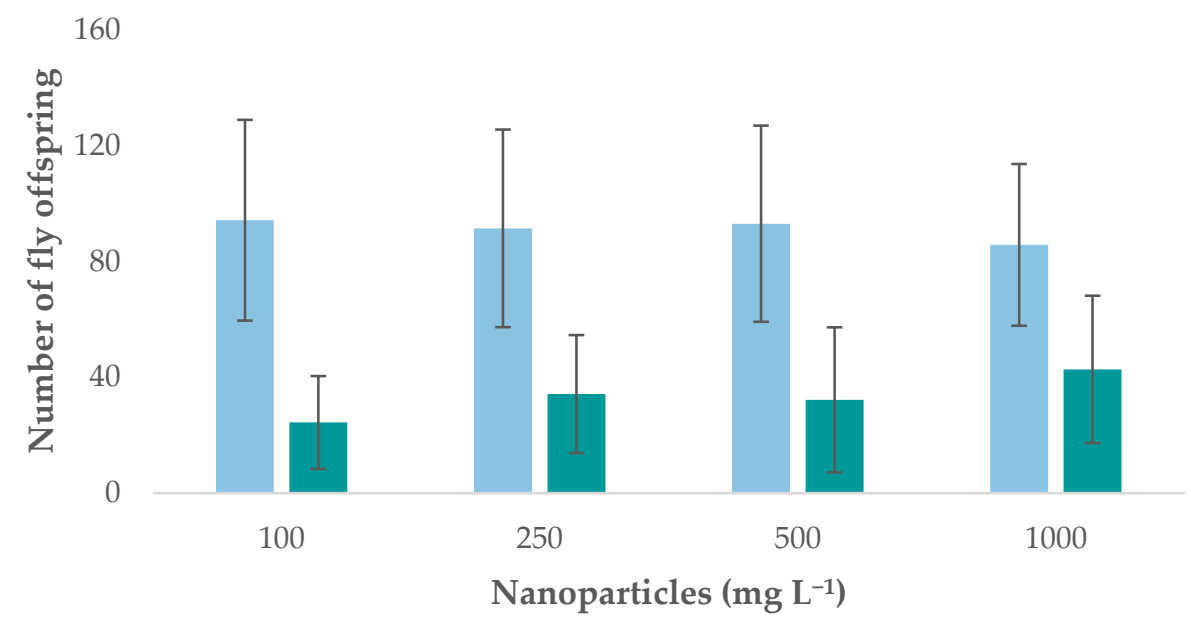

Figure 4. Drosophila's offspring after exposure to $\mathrm{Fe}_{3} \mathrm{O}_{4} \mathrm{NPs}$ and $\mathrm{Ch}-\mathrm{Fe}_{3} \mathrm{O}_{4} \mathrm{NPs}$. Each column shows the average number of adult flies that emerged in each tested concentration, along with the standard deviation $(n=10)$. 
The offspring of control crosses totaled 1197 flies. No statistical differences between the control crosses and crosses exposed to $\mathrm{Fe}_{3} \mathrm{O}_{4} \mathrm{NPs}$ were found; however, significant differences were observed between control crosses and crosses exposed to $\mathrm{Ch}-\mathrm{Fe}_{3} \mathrm{O}_{4} \mathrm{NPs}$. An analysis of variance (ANOVA) and Tukey's HSD test showed significant differences $(p>0.05)$ between fertility of flies exposed to $\mathrm{Fe}_{3} \mathrm{O}_{4} \mathrm{NPs}$ and those exposed to $\mathrm{Ch}-\mathrm{Fe}_{3} \mathrm{O}_{4} \mathrm{NPs}$ (Supplementary Materials, Tables SI-1.1 and SI-1.2). For non-coated NPs, offspring numbers corresponded to $942,914,930$, and 857 flies for $100,250,500$, and $1000 \mathrm{mg} \mathrm{L}^{-1}$, respectively. In the case of $\mathrm{Ch}-\mathrm{Fe}_{3} \mathrm{O}_{4} \mathrm{NPs}$, there were 244, 342, 322, and 427 offspring for 100, 250, 500, and $1000 \mathrm{mg} \mathrm{L}^{-1}$, respectively. Fertility of flies exposed to $\mathrm{Ch}-\mathrm{Fe}_{3} \mathrm{O}_{4} \mathrm{NPs}$, at all concentrations, was significantly lower than flies exposed to non-coated $\mathrm{Fe}_{3} \mathrm{O}_{4} \mathrm{NPs}$.

\subsection{Method Validation}

Overall, the validation of the method to quantitate iron in Drosophila melanogaster was satisfactory, as it showed that: (a) limits of quantification (LOQs) were $6.44 \mathrm{mg} \mathrm{kg}^{-1}$ and $16.9 \mathrm{mg} \mathrm{kg}^{-1}$ for the low and high concentrations, respectively (Table 1); (b) considering both accuracy and precision, the method was optimal for concentrations greater than $20 \mathrm{mg} \mathrm{kg}^{-1}$ (Table 2); (c) despite medium heterogeneity, iron dosage was proven to be in accordance with the desired exposure concentrations for this experiment (Figure 2). Please see Supplementary Materials, SI-2 for linear fit and confidence limits.

Blank measurements are displayed in Table 1; all of them were within the confidence limits. Minimal values that can be quantified with this analytical method are $6.44 \mathrm{mg} \mathrm{kg}^{-1}$ (low range) and $16.9 \mathrm{mg} \mathrm{kg}^{-1}$ (high range). These values were obtained by considering the volume and average mass used in the sample preparation procedure.

Table 1. Blank measurements used for the estimation of limits of detection (LOD) and quantification (LOQ).

\begin{tabular}{cccc}
\hline & & Low Range & High Range \\
\hline 1 & & -0.007 & -0.062 \\
2 & & -0.021 & -0.034 \\
3 & & -0.023 & -0.065 \\
4 & & -0.028 & -0.091 \\
5 & & -0.032 & -0.085 \\
6 & $\mathrm{mg} \mathrm{L}^{-1}$ & -0.015 & -0.098 \\
\hline LOD & $\mathrm{mg} \mathrm{kg}^{-1}$ & 0.027 & 0.071 \\
& $\mathrm{mg} \mathrm{L}^{-1}$ & 1.93 & 5.07 \\
\hline LOQ & $\mathrm{mg} \mathrm{kg}^{-1}$ & 0.090 & 0.237 \\
& & 6.44 & 16.9 \\
\hline
\end{tabular}

Table 2. Accuracy and precision for iron quantitation in Drosophila melanogaster samples.

\begin{tabular}{|c|c|c|c|c|}
\hline $\begin{array}{c}{[\mathrm{Fe}]_{\text {added }}} \\
\left(\mathrm{mg} \mathrm{kg}^{-1}\right)\end{array}$ & $\begin{array}{c}{[\mathrm{Fe}]_{\text {read }}} \\
\left(\mathrm{mg} \mathrm{kg}^{-1}\right)\end{array}$ & Recovery (\%) & $\bar{X}$ & $\%$ RSD \\
\hline 20 & $\begin{array}{l}32.9 \\
31.5\end{array}$ & $\begin{array}{l}164.7 \\
157.6\end{array}$ & 161.18 & 3.14 \\
\hline 45 & $\begin{array}{l}40.4 \\
43.1\end{array}$ & $\begin{array}{l}89.8 \\
95.7\end{array}$ & 92.75 & 4.50 \\
\hline 60 & $\begin{array}{l}57.7 \\
56.5\end{array}$ & $\begin{array}{l}96.2 \\
94.1\end{array}$ & 95.20 & 1.56 \\
\hline
\end{tabular}

As seen in Table 2, fortifications with the matrix showed a high recovery after correcting all values with the average iron concentration present in flies $\left(49.9 \mathrm{mg} \mathrm{kg}^{-1}\right)$. In previous unpublished experiments, it was observed that in the absence of the matrix, iron adhered to crucible walls, causing lower recovery values and lack of reproducibility; 
by using a characterized matrix, this last issue was solved as demonstrated by the relative standard deviation, which was below $5 \%$ in all cases. Recovery values were considered optimum within the $95-105 \%$ range. At lower concentrations, recovery greater than 105\% could be explained by the impossibility of obtaining homogeneous samples and the possibility that the flies used for this particular spiking had a higher biological iron content prior to exposure. Thus, it can be established that this method is valid at concentrations higher than $20.0 \mathrm{mg} \mathrm{kg}^{-1}$.

Prior to fly sample analysis, the iron recovery from the culture medium was assessed. First, each individual component of the culture medium was tested to determine its iron concentration (see Supplementary Materials, SI-3); as none was an important source of metal, we established a correlation between the added amount of NPs and the iron signal measured in the resulting mixture, shown in Figure 5. Small discrepancies were attributable to medium heterogeneity and the fact that added NPs were in a ferrofluid suspension. The obtained linear relationship demonstrates an adequate culture medium preparation and assures that flies were given the proper NPs dosage.

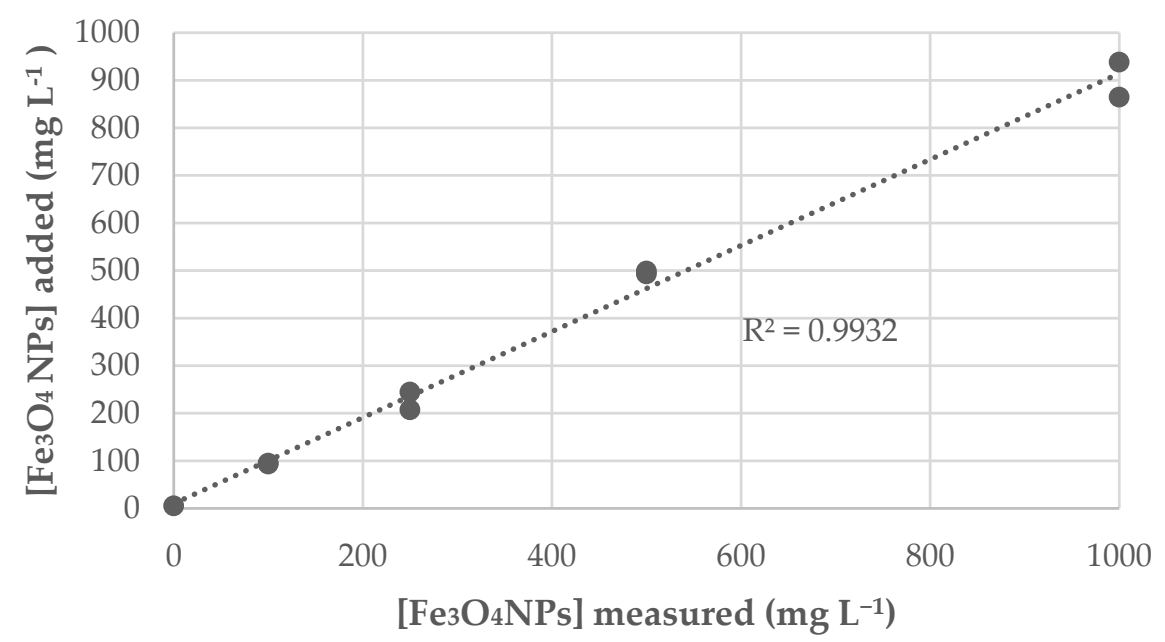

Figure 5. Correlation between added $\mathrm{Fe}_{3} \mathrm{O}_{4} \mathrm{NPs}$ and observed iron concentrations in the culture medium.

\subsection{Iron Bioaccumulation in Drosophila Flies}

After NPs exposure, emerged flies showed iron bioaccumulation in the abdominal cavity when observed with a stereomicroscope (Figure 6), as there were darkened regions around the midgut area. Iron concentration in these flies is shown in Table 3; all data were corrected with the blank's concentration (49.9 mg Fe per kg of non-exposed flies).

Table 3. Bioaccumulated iron in Drosophila melanogaster exposed to non-coated and chitosan-coated magnetite nanoparticles. All concentrations were corrected with blank measurements.

\begin{tabular}{|c|c|c|}
\hline \multirow{2}{*}{ NPs $\left(\mathrm{mg} \mathrm{L}^{-1}\right)$ in Medium } & \multicolumn{2}{|c|}{ [Fe in Flies] $\left(\mathrm{mg} \mathrm{kg}^{-1}\right)$} \\
\hline & Exposure to $\mathrm{Fe}_{3} \mathrm{O}_{4} \mathrm{NPs}$ & Exposure to $\mathrm{Ch}-\mathrm{Fe}_{3} \mathrm{O}_{4} \mathrm{NPs}$ \\
\hline 100 & $6.6 \pm 3.0$ & $11.5 \pm 3.9$ \\
\hline 250 & $21.4 \pm 1.0$ & $10.1 \pm 1.7$ \\
\hline 500 & $<$ Limit of quantification & $8.70 \pm 1.7$ \\
\hline 1000 & $39.5 \pm 2.7$ & $21.9 \pm 5.6$ \\
\hline
\end{tabular}




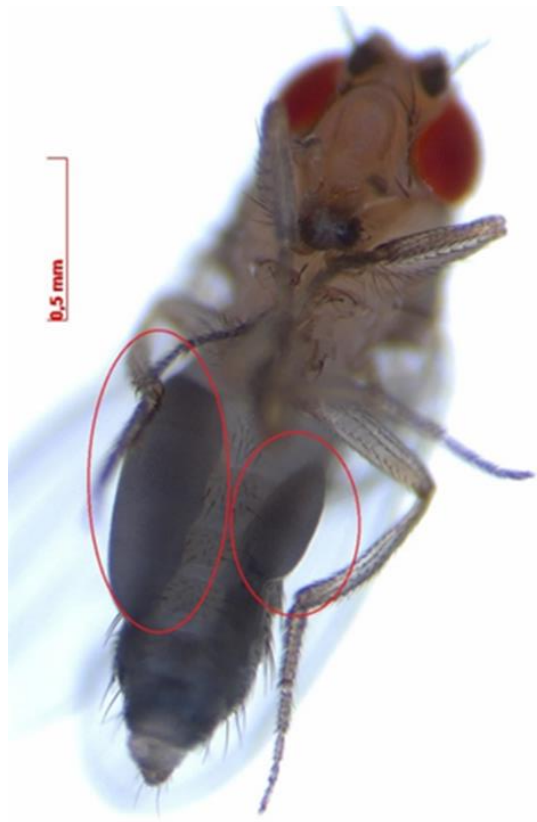

(a)

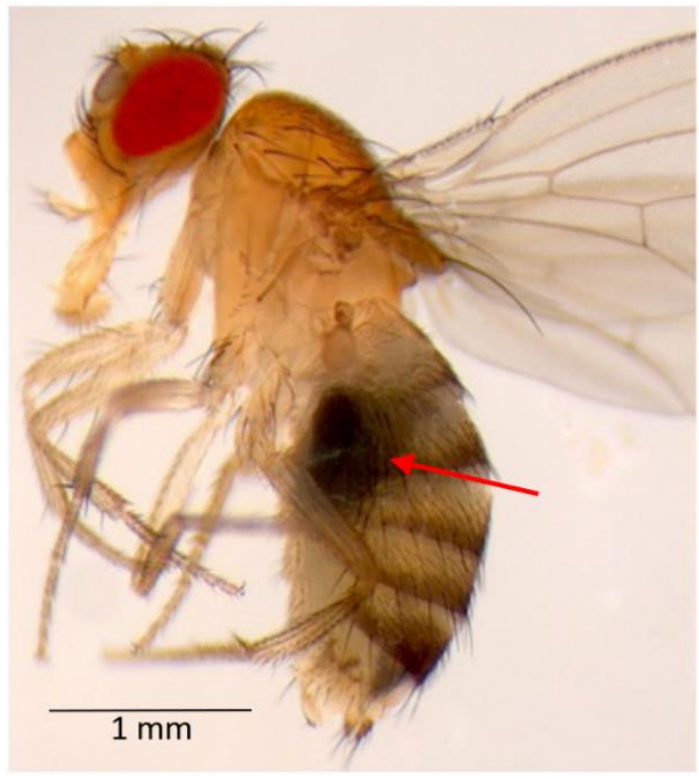

(b)

Figure 6. Iron bioaccumulation: $\mathrm{Fe}_{3} \mathrm{O}_{4} \mathrm{NPs}$ in the abdominal region of flies as observed with a stereomicroscope (a) ventral view and (b) lateral view.

Having measured the iron concentrations in both exposed and non-exposed Drosophila and the matrix of exposure, we calculated the bioaccumulation factor (BAF). As seen in Figure 7, a trend emerged for $\mathrm{Ch}-\mathrm{Fe}_{3} \mathrm{O}_{4} \mathrm{NPs}$ : doses with lower NPs concentrations corresponded to a higher relative buildup of the foreign material compared to doses with higher NPs concentrations in the culture medium. However, this trend did not appear in non-coated NPs assays.

- Ch-coated Non-coated

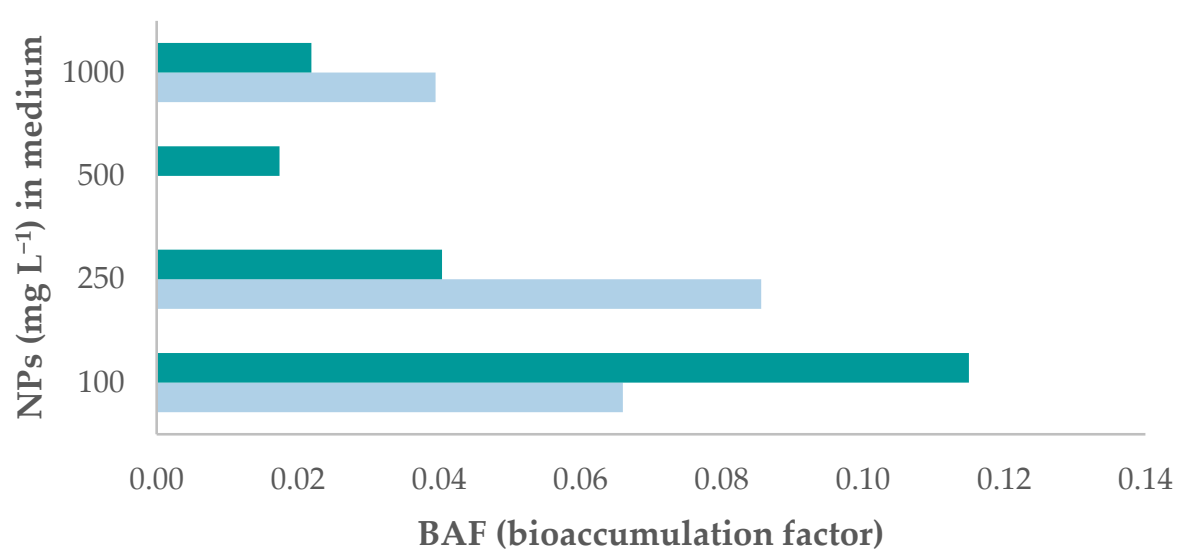

Figure 7. Bioaccumulation factor per nanoparticle concentration in culture medium fed to flies. Results shown for non-coated and chitosan-coated magnetite nanoparticles.

\section{Discussion}

3.1. $\mathrm{Fe}_{3} \mathrm{O}_{4} \mathrm{NPs}^{\prime}$ and $\mathrm{Ch}-\mathrm{Fe}_{3} \mathrm{O}_{4} \mathrm{NPs}^{\prime}$ Effect on Drosophila melanogaster Fertility

Our findings show that $\mathrm{Fe}_{3} \mathrm{O}_{4} \mathrm{NP}$ and $\mathrm{Ch}-\mathrm{Fe}_{3} \mathrm{O}_{4} \mathrm{NP}$ exposure decreased Drosophila melanogaster fertility for all tested concentrations. The ANOVA showed that flies exposed to $\mathrm{Ch}-\mathrm{Fe}_{3} \mathrm{O}_{4} \mathrm{NPs}$ had a significant decrease in fertility compared to flies exposed to $\mathrm{Fe}_{3} \mathrm{O}_{4} \mathrm{NPs}$ 
$(p>0.05)$. The range of fertility in flies exposed to $\mathrm{Ch}-\mathrm{Fe}_{3} \mathrm{O}_{4} \mathrm{NPs}$ was $24.4-42.7$ offspring while in flies exposed to $\mathrm{Fe}_{3} \mathrm{O}_{4} \mathrm{NPs}$, it was 85.7-94.2; the highest fertility level was observed in non-exposed flies $(\bar{x}=119.7)$. Significant differences (Supplementary Materials, SI-1.1) were observed when the fertility of $\mathrm{Ch}-\mathrm{Fe}_{3} \mathrm{O}_{4} \mathrm{NPs}$ and $\mathrm{Fe}_{3} \mathrm{O}_{4} \mathrm{NPs}$-exposed flies and the control group were compared, which demonstrated the negative effect of $\mathrm{Ch}-\mathrm{Fe}_{3} \mathrm{O}_{4} \mathrm{NPs}$ on fertility. In the case of flies exposed to $\mathrm{Fe}_{3} \mathrm{O}_{4} \mathrm{NPs}$, exposure to $1000 \mathrm{mg} \mathrm{L}^{-1}$ produced the lowest fertility level $(\bar{x}=85.7)$, while the other treatments (including the control) showed higher fertility (Supplementary Materials, SI-1.1). In the case of Ch- $\mathrm{Fe}_{3} \mathrm{O}_{4} \mathrm{NPs}$-exposed flies, there were significant differences among the control and both treatment groups (Supplementary Materials, SI-1.1); the lowest NPs concentration $\left(100 \mathrm{mg} \mathrm{L}^{-1}\right)$ produced the lowest fertility level $(\bar{x}=24.4)$. These results are consistent with those reported by Asoufi et al. [30], who also exposed flies to $\mathrm{Fe}_{3} \mathrm{O}_{4} \mathrm{NPs}$ and identified an abnormal trend in the percentage of females in the fecundity stage. Variable behavior appeared in concentration ranges between 50 and $1000 \mathrm{mg} \mathrm{L}^{-1}$, with increased (50-100 $\mathrm{mg} \mathrm{L}^{-1}$ and $200-400 \mathrm{mg} \mathrm{L}^{-1}$ ) and decreased reproduction rates $\left(100-200 \mathrm{mg} \mathrm{L}^{-1}\right.$ and $\left.400-1000 \mathrm{mg} \mathrm{L}^{-1}\right)$. This indicates that certain concentrations trigger a defense mechanism in Drosophila melanogaster, leading to the number of individuals being almost equal to that of the control population.

\subsection{Iron Determination and Bioaccumulation}

Petersen et al. point out the analytical challenges of bioaccumulation experiments in biological matrices [42]. Few studies have measured the accumulated residual iron in in vivo test specimens. For instance, Vega-Alvarez et al. [43] analyzed the effect of nanometric magnetite synthesized by coprecipitation and thermal decomposition methods on embryonic mortality of Drosophila melanogaster. Both types of preparation indicated an increase in mortality percentage: $0-42 \%$ (coprecipitation) and 0-46\% (thermal decomposition); iron concentrations were estimated by extrapolating doses delivered during the microtransfer procedure. Affleck and Walker [44] offer a comprehensive description of techniques used to evaluate known and potential toxicants in Drosophila; however, they do not present information regarding the use of methods to assess metal bioaccumulation in a quantitative manner. One of the essential recommendations from Petersen et al. [42] is to make accurate quantitative measurements of nanomaterial concentration both in the biological species and in the matrix of exposure. Thus, it is imperative to evaluate the analytical method's performance, especially regarding limits of detection (LOD), LOQ, and recovery. We propose a clear protocol to achieve this goal and obtained results with minimal bias. Our methodology included the determination of blank measurements to enable better differentiation of background iron concentration and NPs-attributable iron, as well as the demonstration of the correlation between added and measured metal concentration in the culture medium, to reduce artifacts from matrix heterogeneity that could compromise the interpretation of results.

Our findings show that iron bioaccumulation in flies is related to NPs concentration exposure, with one exception at $500 \mathrm{mg} \mathrm{kg}^{-1}$, where there was a notable decrease in Fe buildup. This concentration may be a threshold that prompts individuals to develop a defense mechanism. Henderson et al. [29] established that iron oxide NPs in concentrations of $10-100 \mu \mathrm{g} \mathrm{mL}^{-1}$ induce an innate immune response that leads to a survival effect of Drosophila larvae and adults. Our results are partially consistent with this hypothesis, as at $100 \mathrm{mg} \mathrm{L}^{-1} \mathrm{Ch}-\mathrm{Fe}_{3} \mathrm{O}_{4} \mathrm{NPs}$, the number of adults decreased, and the highest BAF of all assays occurred. Mehta et al. [31] showed that iron-rich environments result in Drosophila's midgut accumulation of iron-binding protein (ferritin), thus enabling the organism to confine high quantities of this element at this location. This is consistent with the accumulation sites observed in the current study.

Previous research has reported that toxicity observed by low fertility is also related to NPs size, which is the main feature that allows NPs to easily permeate the cell membrane and induce a biological response [45]. Gorth et al. [35] found that smaller NPs (20-30 nm) have a less toxic effect compared to those of $100 \mathrm{~nm}$ and $500-1200 \mathrm{~nm}$ because structurally, 
they do not accumulate within vital organs and thus do not cause a reduction in internal dose administration; however, they also pointed out a higher accumulation of smaller NPs at non-vital sites. Chen et al. [28] used doses of 300 and $600 \mu \mathrm{g} \mathrm{g}^{-1}$ of $\mathrm{Fe}_{3} \mathrm{O}_{4} \mathrm{NPs}$ sized $15 \mathrm{~nm}$. Their results showed a $10 \%$ decrease in adult pupation and emergence rates when the highest dose $\left(600 \mu^{-1} \mathrm{~g} \mathrm{~g}^{-1}\right)$ was administered; they concluded that oral exposure doses threaten all stages of Drosophila melanogaster's development from oogenesis to emergence in adults. In this context and considering that our study used NPs of $15.8 \pm 7.3 \mathrm{~nm}$ in diameter, we can deduce that their small size allowed for slight iron bioaccumulation in Drosophila individuals, but it did not interfere with vital processes, evidenced by the offspring number not being significantly different in the control group.

$\mathrm{Fe}_{3} \mathrm{O}_{4} \mathrm{NPs}$ and $\mathrm{Ch}-\mathrm{Fe}_{3} \mathrm{O}_{4} \mathrm{NPs}$ are not lethal to Drosophila melanogaster as is the case with other metals. For instance, Gorth et al. [35] exposed Drosophila to silver NPs at different concentrations and sizes. The results showed that concentrations of $100 \mathrm{mg} \mathrm{L}^{-1}$ and a size range of 20-30 nm are lethal for adult eggs and flies; for this reason, the bioaccumulation test was performed only with a concentration of $10 \mathrm{mg} \mathrm{L}^{-1}$, which is 10-100 times lower than the concentrations of $\mathrm{Fe}_{3} \mathrm{O}_{4} \mathrm{NPs}$ tested in our experiment. Wu et al. [46] worked with calcium phosphate NPs and showed similar results to ours despite working with very low concentrations ( $3 \mathrm{ppm})$; they found that certain phosphate phases induce a boost in Drosophila melanogaster viability, although it is not clear why. This suggests that there may be other factors to consider during experimental design beyond NP size and concentration. Lankveld et al. [47] reported lower accumulation in rat tissue with smaller AgNPs, which contrasts with the findings from Gorth et al. [35]; the difference may be attributable to the exposure route, as Lankveld et al. [47] injected NPs into the specimens, while Gorth et al. [35] administered them orally. Other studies have demonstrated that a coating modifies the NP's surface charge and thus the interaction it may have with the organism. Feng et al. [48] demonstrated differences in uptake, toxicity, distribution, and clearance of iron oxide NPs administered by injection to rats that depended on both NPs size and coating, even at low doses $(1.5 \mathrm{mg} \mathrm{Fe} / \mathrm{kg}$ ). Furthermore, Jiang et al. [49] found that a positively charged surface, such as one coated with chitosan, enhances electrostatic interaction with Drosophila's midgut, which in turn facilitates cellular uptake. Considering that these results were obtained with particles of about $140 \mathrm{~nm}$ in diameter, and the current study used a smaller diameter, it is feasible that both factors (smaller size and chitosan coating) promote $\mathrm{Ch}-\mathrm{Fe}_{3} \mathrm{O}_{4} \mathrm{NPs}^{\prime}$ absorption and elicit a biological response that results in a decrease of fertility at all tested NPs concentrations.

\section{Materials and Methods}

\section{1. $\mathrm{Fe}_{3} \mathrm{O}_{4} \mathrm{NPs}$ and $\mathrm{Ch}-\mathrm{Fe}_{3} \mathrm{O}_{4} \mathrm{NPs}$ Synthesis and Characterization}

$\mathrm{Fe}_{3} \mathrm{O}_{4} \mathrm{NPs}$ were synthesized using a coprecipitation method [50]. A $50 \mathrm{~mL}$ solution containing $0.30 \mathrm{~g}$ of $\mathrm{FeCl}_{3} \cdot 6 \mathrm{H}_{2} \mathrm{O}(97 \%$, Loba Chemie Mumbai, India) and $0.14 \mathrm{~g}$ of $\mathrm{FeCl}_{2} \cdot 4 \mathrm{H}_{2} \mathrm{O}(98 \%$, BDH Chemicals, London, UK) was prepared. This solution was heated at $60{ }^{\circ} \mathrm{C} \pm 1{ }^{\circ} \mathrm{C}$ for $10 \mathrm{~min}$; afterward, $50 \mathrm{~mL}$ of $2.5 \mathrm{M} \mathrm{NaOH}$ (98\%, Fisher Scientific, Waltham, MA, USA) were added dropwise. Helium gas was used to provide an inert atmosphere. A precipitate was obtained and washed with $10 \mathrm{~mL}$ of deionized water and then with $10 \mathrm{~mL}$ of acetone twice. Finally, the $\mathrm{Fe}_{3} \mathrm{O}_{4} \mathrm{NPs}$ were washed three times for $10 \mathrm{~min}$ with $10 \mathrm{~mL}$ of absolute ethanol (Scharlau 99\%, Senmanat, Spain) in a Branson 3510 ultrasonic bath (Branson, Brookfield, CT, USA) at a frequency of $40 \mathrm{kHz}$. Prior to use, $\mathrm{Fe}_{3} \mathrm{O}_{4} \mathrm{NPs}$ suspension media was changed from ethanol to water by performing three washes with deionized water. $\mathrm{Ch}-\mathrm{Fe}_{3} \mathrm{O}_{4} \mathrm{NPs}$ initial reaction mixture contained: $50 \mathrm{~mL}$ of $\mathrm{FeCl}_{3} \cdot 6 \mathrm{H}_{2} \mathrm{O}$ $0.32 \mathrm{M}$ with $50 \mathrm{~mL}$ of $\mathrm{FeCl}_{2} \cdot 4 \mathrm{H}_{2} \mathrm{O} 0.2 \mathrm{M}$ and $50 \mathrm{~mL}$ chitosan $0.25 \%$. This mixture was heated at $50{ }^{\circ} \mathrm{C}$ for 10 min with constant stirring before adding $20 \mathrm{~mL}$ of $\mathrm{NH}_{4} \mathrm{OH} 20 \%$ $v / v$ (Merck, Darmstadt, Germany) dropwise. Helium was also used to provide an inert atmosphere for $20 \mathrm{~min}$. Obtained NPs were separated with the help of a Nd-Fe-B magnet (Supermagnete, Gottmadingen, Germany). Subsequent washing and activation steps were performed as described above. 
All synthesized NPs were characterized by means of transmission electron microscopy (TEM, FEI Tecnai G2 Spirit Twin, Hillsboro, OR, USA) and X-ray diffraction (XRD) (PANalytical Empyrean, Almelo, The Netherlands). For TEM, a FEI Spirit Twin with LaB6 filament was used, operating at $80 \mathrm{kV}$. The diffractometer had a $\theta-2 \theta$ configuration (Bragg-Brentano geometry) and was equipped with a $\mathrm{Cu}$ X-ray tube $(\mathrm{K} \alpha$ radiation $\lambda=1.54056 \AA)$ operating at $40 \mathrm{kV}$ and $40 \mathrm{mV}$; the analyzed sample was previously dried on a microscope slide at $40{ }^{\circ} \mathrm{C}$ to avoid any thermal degradation. A compensation for the $0.5 \mathrm{~mm}$ formed layer was provided in the alignment of the diffractometer sample holder device. The particle size distribution was determined by dynamic light scattering using a Malvern Zetasizer ZS90 model (Malvern Panalytical Ltd., Malvern, UK) at $25^{\circ} \mathrm{C}$ and a concentration of $1 \mathrm{mg} \mathrm{mL}{ }^{-1}$. The polydispersity index (PDI) was obtained simultaneously with the particle size.

\section{2. $\mathrm{Fe}_{3} \mathrm{O}_{4} \mathrm{NPs}$ ' and $\mathrm{Ch}-\mathrm{Fe}_{3} \mathrm{O}_{4} \mathrm{NPs}^{\prime}$ Effect on Drosophila melanogaster Fertility}

The fertility of Drosophila melanogaster flies (Oregon strain) was assessed after exposure to four concentrations $\left(100,250,500\right.$, and $\left.1000 \mathrm{mg} \mathrm{L}^{-1}\right)$. The flies were orally exposed by adding the corresponding concentration of NPs to banana culture medium [51], which was then fed to the flies. Ten crosses (five females $\times$ five males) were done for each concentration of NPs as well as control crosses without NPs. The parents were removed on the sixth day of the experiment to avoid overlapping of generations. The offspring were counted for 14 days after the first emerged fly. The parents and crosses were maintained in controlled conditions: $22{ }^{\circ} \mathrm{C}\left( \pm 1^{\circ} \mathrm{C}\right), 48 \%$ humidity, 12-h photoperiod, and banana culture medium.

\subsection{Iron Determination and Method Validation}

Iron quantification was performed as per the AOAC 999.11 protocol using the AAnalyst 400 atomic absorption spectrophotometer (Perkin Elmer, Waltham, MA, USA). Between 0.3 and $0.4 \mathrm{~g}$ of samples were weighed and calcined at $450{ }^{\circ} \mathrm{C}$ in a furnace (Comecta, Barcelona, Spain) for eight hours. Later, ashes were treated with $0.1 \mathrm{~N} \mathrm{HNO}_{3}(69 \%$, Loba Chemie) for one hour, filtered, and diluted to the mark in a $25 \mathrm{~mL}$ volumetric flask. Samples consisted of each component of the culture medium, culture medium as a whole, and flies exposed and unexposed to $\mathrm{Fe}_{3} \mathrm{O}_{4} \mathrm{NPs}$ and $\mathrm{Ch}-\mathrm{Fe}_{3} \mathrm{O}_{4} \mathrm{NPs}$.

To assure the quality of results, a partial validation was performed. Uncertainty calculation was ruled out because of certified reference material unavailability. For the analysis, $1000 \mathrm{mg} \mathrm{Fe} \mathrm{L}^{-1}$ of certified standard solution (Labequim, Puebla, Mexico) were used to prepare the calibration solutions and spiked samples. Two curves were constructed for low $\left(0.125,0.500,0.750,1.000\right.$, and $\left.1.500 \mathrm{mg} \mathrm{L}^{-1}\right)$ and high $(1.000,2.000,3.000,4.000$, and $5.000 \mathrm{mg} \mathrm{L}^{-1}$ ) ranges to enable more flexibility regarding sample concentrations; $50 \mathrm{~mL}$ of each dilution were prepared and maintained at $4{ }^{\circ} \mathrm{C}$ until needed. All calibrations were a function of atomic absorption spectrometry (AAS) measurements versus concentration, after which a linear regression was performed to estimate upper and lower confidence limits (UCL and LCL, respectively) (Equation (1)). The value of T was selected from Student's t-distribution at n-1 degrees of freedom (2.569) and a 95\% confidence level:

$$
y=\left(a \pm T \times \varepsilon_{a}\right)+\left(b \pm T \times \varepsilon_{b}\right) \times x
$$

The LOD refers to the lowest quantity of a substance that can be distinguished from the absence of that substance (a blank sample) within a stated confidence limit (generally $1 \%$ ), while the LOQ is the smallest quantity that can be assured to be present. Thus, the LOD and LOQ were determined from the signals produced from six blank samples ( $0 \mathrm{ppm}$ of iron) per calibration curve (12 in total). All these solutions were prepared according to AOAC 999.11 protocol. LOD and LOQ values were obtained by multiplying the standard deviation of all blanks by 3 and 10, respectively.

To assess accuracy and precision, four spiked samples were prepared with the following amounts of added analyte: 18.5, 20.0, 45.0, and $60.0 \mathrm{mg} \mathrm{kg}^{-1}$. Between 0.2 and $0.3 \mathrm{~g}$ of Drosophila melanogaster flies were used as the matrix. Afterward, $1 \mathrm{~mL}$ of each iron 
fortification was added and evaporated without boiling prior to calcination at $450{ }^{\circ} \mathrm{C}$ for eight hours. Ashes were dissolved with $10 \mathrm{~mL}$ of nitric acid $0.1 \mathrm{~N}$ and transferred to a $50 \mathrm{~mL}$ volumetric flask. Duplicate samples, except iron fortifications at $1.85 \mathrm{~mL}$, were analyzed by AAS. Accuracy was determined as percent of recovery (Equation (2)), while precision was assessed by means of relative standard deviation (\%RSD). For these parameters, acceptance criteria were established as $100 \pm 5 \%$ for recovery, and RSD $<10 \%$.

$$
\text { Recovery }(\%)=\frac{\text { Instrument reading }}{\text { True value }} \times 1000
$$

Considering that the assays for accuracy and precision required the use of Drosophila melanogaster flies as the matrix, it was necessary to assess their existing iron content. This was done with eight independent samples, all of which underwent the same aforementioned procedure, without the iron solution addition.

\subsection{Iron Bioaccumulation in Drosophila Flies}

Quantification of iron accumulated in the abdominal cavity of exposed flies was estimated in the offspring obtained in the assay described in Section 2.4 as per the AOAC 999.11 protocol. Prior to analysis, flies were isolated for $24 \mathrm{~h}$ after emerging, immobilized in a $\mathrm{CO}_{2}$ chamber, and stored at $0{ }^{\circ} \mathrm{C}$. Average iron concentrations in flies and the medium were later used to estimate the BAF as the quotient of metal concentration in banana culture medium and in Drosophila bodies [42,52].

\subsection{Statistical Analysis}

To compare the fertility of flies exposed to the $\mathrm{Fe}_{3} \mathrm{O}_{4} \mathrm{NPs}$ and $\mathrm{Ch}-\mathrm{Fe}_{3} \mathrm{O}_{4} \mathrm{NPs}$ treatments and the control, a one-way ANOVA, Duncan's test, and Tukey's HSD test were performed. The analysis was carried out using the SPSS statistical package, version 26.0. Significant difference was accepted when $p<0.05$.

\section{Conclusions}

This study validated an analytical method for the determination of the bioaccumulation of iron in Drosophila melanogaster flies fed with magnetite NPs; this protocol proved to be versatile for the direct measurement of metal content in flies, as it can be applied with confidence for both coated and non-coated NPs to obtain a valid correlation between the toxicant and the observable effect. Our findings highlight that iron bioaccumulation is associated with NPs concentration. All tested concentrations of chitosan-coated NPs produced a toxic effect, which decreased the fertility of exposed Drosophila flies; however, for non-coated NPs, only the $1000 \mathrm{mg} \mathrm{L}^{-1}$ concentration produced such an effect. In addition, it was determined that a dose of $500 \mathrm{mg} \mathrm{L}^{-1}$ produced no effect for both coated and non-coated NPs, resulting in values close to that of the control population for both fertility and iron bioaccumulation, suggesting this concentration can be used with any type of coating for in vivo studies with this species.

Supplementary Materials: The following are available online. Table SI-1.1: Statistical analysis of fly fertility after exposure to $\mathrm{Fe}_{3} \mathrm{O}_{4} \mathrm{NPs}, \mathrm{Ch}-\mathrm{Fe}_{3} \mathrm{O}_{4} \mathrm{NPs}$, and control; Table SI-1.2: Tukey's HSD test results for control, $\mathrm{Fe}_{3} \mathrm{O}_{4} \mathrm{NPs}$, and $\mathrm{Ch}-\mathrm{Fe}_{3} \mathrm{O}_{4}$ NPs groups; Table SI-2.1: Linear fit, upper, and lower confidence limits (UCL and LCL) for each iron concentration within the studied ranges; Table SI-3.1: Iron concentrations in individual culture medium components.

Author Contributions: Conceptualization, F.P. and D.V.; methodology, F.P., D.V., E.J.; validation, F.P., D.V., E.J.; formal analysis, S.C., A.D.; resources, F.P., J.M., M.d.1.N.P.; writing-original draft preparation, F.P., D.V., E.J., J.L.G.-C., A.D.; writing—review and editing, F.P., D.V., E.J., J.M., M.d.1.N.P.; project administration, F.P.; funding acquisition, F.P. All authors have read and agreed to the published version of the manuscript.

Funding: This research was funded by Pontificia Universidad Católica del Ecuador, Toxicity determination of iron nanoparticles in Drosoph. melanogaster, grant number LI3258. 
Institutional Review Board Statement: Not applicable.

Informed Consent Statement: Not applicable.

Data Availability Statement: The data presented in this study are available on request from the corresponding author.

Acknowledgments: Thanks to Lucía Rodríguez (UPS) and Paulino Duel (UIB) for their support in this study.

Conflicts of Interest: The authors declare no conflict of interest.

Sample Availability: Samples of the compounds are not available from the authors.

\section{References}

1. Gupta, A.K.; Gupta, M. Synthesis and surface engineering of iron oxide nanoparticles for biomedical applications. Biomaterials 2005, 26, 3995-4021. [CrossRef]

2. Siegel, R.W. Introduction and Overview. In Nanostructure Science and Technology. A Worldwide Study; Siegel, R.W., Hu, E., Roco, M.C., Eds.; WTEC, Loyola College in Maryland: Baltimore, MD, USA, 1999; pp. 1-15.

3. Goya, G.F.; Berquó, T.S.; Fonseca, F.C.; Morales, M.P. Static and dynamic magnetic properties of spherical magnetite nanoparticles. J. Appl. Phys. 2003, 94, 3520-3528. [CrossRef]

4. Abbaspour, N.; Hurrell, R.; Kelishadi, R. Review on iron and its importance for human health. J. Res. Med. Sci. 2014, 19, 164-174.

5. Balmadrid, C.; Bono, M. Recognizing and Managing Iron Toxicity. Emerg. Med. 2009, 41, 36-41.

6. Dear, J.W.; Bateman, D.N. Benzodiazepines. Medicine 2016, 44, 173-174.

7. Albretsen, J. The toxicity of iron, an essential element. Vet. Med. Bonn. Springs Then Edwardsv. 2006, 101, 82-90.

8. Arias, J.L.; López-Viota, M.; Ruiz, M.A. Partículas superparamagnéticas ultrapequeñas de óxido de hierro para aplicaciones biomédicas. Ars Pharm. 2008, 49, 101-111.

9. Buschow, K.H.J. Handbook of Magnetic Materials; Elsevier, B.V.: Amsterdam, The Netherlands, 2006.

10. Bououdina, M.; Davim, J.P. Handbook of Research on Nanoscience, Nanotechnology, and Advanced Materials; Bououdina, M., Davim, J.P., Eds.; Advances in Chemical and Materials Engineering; IGI Global: Hershey, PA, USA, 2014; ISBN 9781466658240.

11. Odenbach, S. Ferrofluids and their applications. MRS Bull. 2013, 38, 921-924. [CrossRef]

12. Fischer, B.; Mao, L.; Gungormus, M.; Tamerler-Behar, C.; Sarikaya, M.; Koser, H. Biomedical Engineered Ferrofluids. MRS Proc. 2007, 1032, 1007-1032. [CrossRef]

13. Li, L.; Chen, D.; Zhang, Y.; Deng, Z.; Ren, X.; Meng, X.; Tang, F.; Ren, J.; Zhang, L. Magnetic and fluorescent multifunctional chitosan nanoparticles as a smart drug delivery system. Nanotechnology 2007, 18, 40-51. [CrossRef]

14. Sasaki, T.; Iwasaki, N.; Kohno, K.; Kishimoto, M.; Majima, T.; Nishimura, S.-I.; Minami, A. Magnetic nanoparticles for improving cell invasion in tissue engineering. J. Biomed. Mater. Res. Part A 2008, 86A, 969-978. [CrossRef]

15. Rhee, I.; Hong, S.; Chang, Y. Chitosan-Coated Ferrite $\left(\mathrm{Fe}_{3} \mathrm{O}_{4}\right)$ Nanoparticles as a T2 Contrast Agent for Magnetic Resonance Imaging. J. Korean Phys. Soc. 2010, 56, 868-873. [CrossRef]

16. Xie, W.; Wang, J. Immobilized lipase on magnetic chitosan microspheres for transesterification of soybean oil. Biomass Bioenergy 2012, 36, 373-380. [CrossRef]

17. Zhou, Y.-T.; Nie, H.-L.; Branford-White, C.; He, Z.-Y.; Zhu, L.-M. Removal of $\mathrm{Cu}^{2+}$ from aqueous solution by chitosan-coated magnetic nanoparticles modified with $\alpha$-ketoglutaric acid. J. Colloid Interface Sci. 2009, 330, 29-37. [CrossRef]

18. Haldorai, Y.; Kharismadewi, D.; Tuma, D.; Shim, J.-J. Properties of chitosan/magnetite nanoparticles composites for efficient dye adsorption and antibacterial agent. Korean J. Chem. Eng. 2015, 32, 1688-1693. [CrossRef]

19. López, R.G.; Pineda, M.G.; Hurtado, G.; de León, R.D.; Fernández, S.; Saade, H.; Bueno, D. Chitosan-coated magnetic nanoparticles prepared in one step by reverse microemulsion precipitation. Int. J. Mol. Sci. 2013, 14, 19636-19650. [CrossRef]

20. Osuna, Y.; Gregorio-Jauregui, K.M.; Gaona-Lozano, J.G.; de la Garza-Rodríguez, I.M.; Ilyna, A.; Barriga-Castro, E.D.; Saade, H.; López, R.G. Chitosan-Coated Magnetic Nanoparticles with Low Chitosan Content Prepared in One-Step. J. Nanomater. 2012, 2012, 1-7. [CrossRef]

21. Shukla, S.; Jadaun, A.; Arora, V.; Sinha, R.K.; Biyani, N.; Jain, V.K. In vitro toxicity assessment of chitosan oligosaccharide coated iron oxide nanoparticles. Toxicol. Rep. 2015, 2, 27-39. [CrossRef]

22. Mohammadi-Samani, S.; Miri, R.; Salmanpour, M.; Khalighian, N.; Sotoudeh, S.; Erfani, N. Preparation and assessment of chitosan-coated superparamagnetic Fe3O4 nanoparticles for controlled delivery of methotrexate. Res. Pharm. Sci. 2013, 8, 25-33.

23. Pandey, U.B.; Nichols, C.D. Human disease models in Drosophila melanogaster and the role of the fly in therapeutic drug discovery. Pharmacol. Rev. 2011, 63, 411-436. [CrossRef]

24. Baker, D.A.; Beckingham, K.M.; Armstrong, J.D. Functional dissection of the neural substrates for gravitaxic maze behavior inDrosophila melanogaster. J. Comp. Neurol. 2007, 501, 756-764. [CrossRef] [PubMed] 
25. Everman, E.R.; Delzeit, J.L.; Hunter, F.K.; Gleason, J.M.; Morgan, T.J. Costs of cold acclimation on survival and reproductive behavior in Drosophila melanogaster. PLOS ONE 2018, 13, e0197822. [CrossRef] [PubMed]

26. Parvathi, D.; Amritha, A.; Paul, S. Wonder animal model for genetics studies-Drosophila melanogaster-Its life cycle and breeding methods-A review. Sri Ramachandra J. Med. 2009, 2, 33-38.

27. Chifiriuc, M.C.; Ratiu, A.C.; Popa, M.; Ecovoiu, A. Al Drosophotoxicology: An emerging research area for assessing nanoparticles interaction with living organisms. Int. J. Mol. Sci. 2016, 17, 36. [CrossRef]

28. Chen, H.; Wang, B.; Feng, W.; Du, W.; Ouyang, H.; Chai, Z.; Bi, X. Oral magnetite nanoparticles disturb the development of Drosophila melanogaster from oogenesis to adult emergence. Nanotoxicology 2015, 9, 302-312. [CrossRef]

29. Henderson, B.W.; Ajjuri, R.R.; Boyd, S.; Daigle, G.; Bao, Y.; O’Donnell, J.M. Low Doses of Iron-Oxide Nanoparticles Have a Detrimental Effect on Reproduction and Development. In Proceedings of the 54th Annual Drosophila Research, Washington, DC, USA, 3-7 April 2013; Wardman Park, M., Ed.; The Genetics Society of America: Washington, DC, USA, 2013.

30. Asoufi, H.; Al Antary, T.; Awwad, A. Effect of Green Synthesized Magnetite $\left(\mathrm{Fe}_{3} \mathrm{O}_{4}\right)$ Nanoparticles on the Green Peach Aphid Myzus persicae Sulzer (Homoptera: Aphididea) Longevity and Fecundity. Adv. Environ. Biol. 2018, 12. [CrossRef]

31. Mehta, A.; Deshpande, A.; Bettedi, L.; Missirlis, F. Ferritin accumulation under iron scarcity in Drosophila iron cells. Biochimie 2009, 91, 1331-1334. [CrossRef]

32. Vecchio, G.; Galeone, A.; Malvindi, M.A.; Cingolani, R.; Pompa, P.P. Ranking the in vivo toxicity of nanomaterials in Drosophila melanogaster. J. Nanoparticle Res. 2013, 15, 1936. [CrossRef]

33. Tian, H.; Eom, H.-J.; Moon, S.; Lee, J.; Choi, J.; Chung, Y.D. Development of biomarker for detecting silver nanoparticles exposure using a GAL4 enhancer trap screening in Drosophila. Environ. Toxicol. Pharmacol. 2013, 36, 548-556. [CrossRef]

34. Roy, N.; Gaur, A.; Jain, A.; Bhattacharya, S.; Rani, V. Green synthesis of silver nanoparticles: An approach to overcome toxicity. Environ. Toxicol. Pharmacol. 2013, 36, 807-812. [CrossRef]

35. Gorth, D.J.; Rand, D.M.; Webster, T.J. Silver nanoparticle toxicity in Drosophila: Size does matter. Int. J. Nanomed. 2011, 6, 343. [CrossRef]

36. Kumar, B.; Smita, K.; Cumbal, L.; Debut, A.; Camacho, J.; Hernández-Gallegos, E.; Chávez-López, M.D.G.; Gri-jalva, M.; Angulo, Y.; Rosero, G. Pomosynthesis and biological activity of silver nanoparticles using Passiflora tripartita fruit extracts. Adv. Mater. Lett. 2015, 6, 127-132. [CrossRef]

37. Demir, E.; Turna, F.; Vales, G.; Kaya, B.; Creus, A.; Marcos, R. In vivo genotoxicity assessment of titanium, zirconium and aluminium nanoparticles, and their microparticulated forms, in Drosophila. Chemosphere 2013, 93, 2304-2310. [CrossRef]

38. Goodman, C.M.; McCusker, C.D.; Yilmaz, T.; Rotello, V.M. Toxicity of Gold Nanoparticles Functionalized with Cationic and Anionic Side Chains. Bioconjug. Chem. 2004, 15, 897-900. [CrossRef]

39. Kumar, B.; Smita, K.; Debut, A.; Cumbal, L. Utilization of Persea americana (Avocado) oil for the synthesis of gold nanoparticles in sunlight and evaluation of antioxidant and photocatalytic activities. Environ. Nanotechnol. Monit. Manag. 2018, 10, $231-237$. [CrossRef]

40. Lu, X.; Chen, C.; Wen, X.; Han, P.; Jiang, W.; Liang, G. Highly charged, magnetically sensitive magnet-ite/polystyrene colloids: Synthesis and tunable optical properties. J. Mater. Sci. 2019, 54, 7628-7636. [CrossRef]

41. Anilkumar, T.S.; Lu, Y.J.; Chen, J.P. Optimization of the preparation of magnetic liposomes for the combined use of magnetic hyperthermia and photothermia in dual magneto-photothermal cancer therapy. Int. J. Mol. Sci. 2020, 21, 5187. [CrossRef]

42. Petersen, E.J.; Mortimer, M.; Burgess, R.M.; Handy, R.; Hanna, S.; Ho, K.T.; Johnson, M.; Loureiro, S.; Selck, H.; Scott-Fordsmand, J.J.; et al. Strategies for robust and accurate experimental approaches to quantify nanomaterial bioaccumulation across a broad range of organisms. Environ. Sci. Nano 2019, 6, 1619-1656. [CrossRef]

43. Vega-Alvarez, S.; Herrera, A.; Rinaldi, C.; Carrero-Martínez, F.A. Tissue-specific direct microtransfer of nanomaterials into Drosophila embryos as a versatile in vivo test bed for nanomaterial toxicity assessment. Int. J. Nanomed. 2014, 9, $2031-2041$. [CrossRef]

44. Affleck, J.G.; Walker, V.K. Drosophila as a Model for Developmental Toxicology: Using and Extending the Drosophotoxicology Model. In Methods in Molecular Biology; Humana Press Inc.: Totowa, NJ, USA, 2019; Volume 1965, pp. 139-153.

45. Tejaswi, J.; Anirudh, K.V.S.; Majeti, L.R.; Kotagiri, D.; Shaik, K.B.; Chaitanya, K.V. Investigation of Biological Activity of Nanoparticles Using Cell Lines. In Model Organisms to Study Biological Activities and Toxicity of Nanoparticles; Springer: Singapore, 2020; pp. 117-138.

46. Wu, V.M.; Uskoković, V. Population Effects of Calcium Phosphate Nanoparticles in Drosophila melanogaster: The Effects of Phase Composition, Crystallinity, and the Pathway of Formation. ACS Biomater. Sci. Eng. 2017, 3, 2348-2357. [CrossRef]

47. Lankveld, D.P.K.; Oomen, A.G.; Krystek, P.; Neigh, A.; Troost-de Jong, A.; Noorlander, C.W.; Van Eijkeren, J.C.H.; Geertsma, R.E.; De Jong, W.H. The kinetics of the tissue distribution of silver nanoparticles of different sizes. Biomaterials 2010, 31, 8350-8361. [CrossRef]

48. Feng, Q.; Liu, Y.; Huang, J.; Chen, K.; Huang, J.; Xiao, K. Uptake, distribution, clearance, and toxicity of iron oxide nanoparticles with different sizes and coatings. Sci. Rep. 2018, 8, 2082. [CrossRef]

49. Jiang, S.; Teng, C.P.; Puah, W.C.; Wasser, M.; Win, K.Y.; Han, M.Y. Oral Administration and Selective Uptake of Polymeric Nanoparticles in Drosophila Larvae as an in Vivo Model. ACS Biomater. Sci. Eng. 2015, 1, 1077-1084. [CrossRef]

50. Vela, D.; Rondal, J.; Cárdenas, S.; Gutiérrez-Coronado, J.; Jara, E.; Debut, A.; Pilaquinga, F. Assessment of the Toxic Effects of Chitosan-Coated Magnetite Nanoparticles on Drosophila melanogaster. Am. J. Appl. Sci. 2020, 17, 204-213. [CrossRef] 
51. Rafael, V.; Arcos, L. Ecología y Distribución del género Drosophila en Guayllabamba y el Quinche, provincia de Pichincha-Ecuador. Rev. Pontif. Univ. Católica Ecuad. 2000, 65, 130-155.

52. Augustyniak, M.; Babczyńska, A.; Migula, P.; Wilczek, G.; Łaszczyca, P.; Kafel, A.; Augustyniak, M. Joint effects of dimethoate and heavy metals on metabolic responses in a grasshopper (Chorthippus brunneus) from a heavy metals pollution gradient. Comp. Biochem. Physiol. Part C Toxicol. Pharmacol. 2005, 141, 412-419. [CrossRef] 